\title{
ESTUDO DA CINÉTICA DE SECAGEM DO GENGIBRE (Zingiber officinale Roscoe)
}

\section{J. C.ZANETTE ${ }^{1}$, P.T. JUCHEN ${ }^{1}$, M.T.VEIT ${ }^{1}$, G.C.GONÇALVES ${ }^{2}$, M. R. FAGUNDES- $\mathrm{KLEN}^{1}$}

${ }^{1}$ Universidade Estadual do Oeste do Paraná, Departamento de Engenharia Química

${ }^{2}$ Universidade Tecnológica Federal do Paraná, Curso de Processos Químicos

E-mail para contato: jessica_zanette@hotmail.com

\begin{abstract}
RESUMO - O trabalho tem como objetivo investigar a influência da temperatura na cinética de secagem da pasta de gengibre. A pasta de gengibre foi seca em estufa com circulação forçada de ar nas temperaturas de 45,55 e $65^{\circ} \mathrm{C}$ e as curvas de secagem foram obtidas pela pesagem da bandeja com gengibre até atingir peso constante. Os experimentos foram realizados em quadruplicata. Os dados experimentais das curvas de secagem foram ajustados aos modelos matemáticos disponíveis na literatura. Os resultados mostraram que: a) o tempo de secagem diminui com o aumento da temperatura; b) entre as temperaturas estudadas, a de $55{ }^{\circ} \mathrm{C}$ foi aquela que apresentou um melhor resultado quanto a coloração do gengibre seco; c) a curva da taxa de secagem apresentou um período de taxa constante e um período de taxa decrescente; d) o melhor ajuste dos dados cinéticos experimentais foi obtido com o modelo de Page em todas as temperaturas avaliadas.
\end{abstract}

\section{INTRODUÇÃO}

O gengibre (Zingiber officinale Roscoe) é uma planta pertencente a família botânica Zingiberaceae. Seu rizoma é muito utilizado pelo emprego alimentar e industrial, principalmente como matéria-prima para fabricação de bebidas, perfumes e produtos de confeitaria como pães, bolos, biscoitos e geléias (ELPO e NEGRELLE, 2004). Além disso, segundo Mendes (2005), o gengibre é muito conhecido popularmente pelo uso medicinal, como excitante, carminativo e estomacal. Várias propriedades do gengibre foram comprovadas em experimentos científicos, citando-se as atividades antiinflamatórias, antiemética e antináusea, dentre outras. Apesar da maior parte do comércio de gengibre ser feita na forma in natura, ele também é realizado nas formas de conserva, cristalizado e seco. Este gengibre seco, com uma umidade de $12 \%$, é comercializado em peças íntegras, laminado ou ainda em pó. Esta última forma é utilizada em menor volume dado que o processo de moagem é geralmente realizado no país importador (ELPO et al., 2005).

Como o gengibre é um produto com alto teor de umidade (cerca de $80 \%$ ), a secagem torna-se uma alternativa para sua conservação, além de permitir o transporte do produto sem necessidade de refrigeração. 
A secagem de sólidos é uma das mais antigas e usuais operações unitárias encontradas nos mais diversos processos usados em indústrias agrícolas, químicas, alimentícias, dentre outras (PARK et al., 2008). É também uma das operações mais complexas e menos entendida, devido à dificuldade e deficiência da descrição matemática dos fenômenos envolvidos de transferência simultânea de calor, massa e quantidade de movimento no sólido.

Misturas em equilíbrio não podem ter sua umidade de equilíbrio prevista e esta deverá ser determinada experimentalmente. Assim, é necessário, na maioria dos casos, obter algumas medidas experimentais de taxas de secagem (GEANKOPLIS, 1993). A curva da taxa de secagem é representada em função do teor de umidade, e representa a evolução da transferência de calor e massa simultânea, podendo apresentar três períodos: o período inicial, também conhecido como período de indução, o período de taxa constante, e o período de taxa decrescente.

Para o desenvolvimento e aperfeiçoamento de equipamentos utilizados na secagem, a simulação e a obtenção de informações teóricas a respeito do comportamento de cada produto durante a remoção de água é de fundamental importância. Para questões de simulação utilizase um modelo matemático que represente, de forma satisfatória, a perda de água do produto durante o período de secagem. Esses modelos, geralmente, baseiam-se em variáveis externas ao produto, como a temperatura e a umidade relativa do ar de secagem. As equações semiempíricas têm como base a lei de resfriamento de Newton para transferência de calor por convecção, presumindo-se que, durante a secagem, as condições sejam isotérmicas e que a transferência de água seja restrita à superfície do produto (RESENDE et al., 2009).

Os parâmetros dos modelos de secagem em camada fina são calculados em função das variáveis que influenciam a taxa de secagem. Em geral, essas variáveis são sempre a temperatura e o teor de umidade inicial do produto (JÚNIOR e CORRÊEA, 2009).

Com base no exposto, este artigo tem como intuito investigar a influência da temperatura na cinética de secagem do gengibre (Zingiber officinale Roscoe), em estufa com circulação forçada de ar. Para tanto foram obtidas: i) as curvas da cinética de secagem; ii) as curvas da taxa de secagem; iii) os parâmetros de ajuste dos dados cinéticos experimentais de secagem utilizando modelos matemáticos disponíveis na literatura.

\section{MATERIAIS E MÉTODOS}

A matéria-prima gengibre utilizada nos experimentos foi adquirida no comércio local da cidade de Toledo-PR, sendo armazenada sob refrigeração à $5{ }^{\circ} \mathrm{C}$. Para a realização dos experimentos, os rizomas foram lavados em água corrente, removendo-se o excesso da água com um pano limpo e seco. Com auxílio de uma faca, os "dedos" com defeitos e as partes com podridão foram retiradas e o rizoma descascado. $\mathrm{O}$ gengibre sem casca foi cortado em pedaços menores e triturado com o auxílio de um liquidificador doméstico até formar uma pasta. 


\subsection{Curvas de Secagem e Taxas de Secagem}

Realizadas as etapas de lavagem, corte e trituração da matéria-prima, a pasta de gengibre foi disposta em uma bandeja circular de alumínio (14 cm de diâmetro) de maneira a formar uma camada delgada sobre sua base, sendo levada para a secagem na estufa com circulação forçada de ar, previamente aquecida as condições de secagem desejadas.

As amostras foram submetidas a secagem nas temperaturas de 45,55 e $65^{\circ} \mathrm{C}$. Essa faixa foi estabelecida em virtude de em temperaturas elevadas (acima de $90{ }^{\circ} \mathrm{C}$ ) poderem ocorrer alterações indesejáveis em produtos alimentícios, como desnaturação de proteínas, comprometendo a qualidade dos mesmos.

As curvas de secagem foram obtidas mediante a pesagem do conjunto (bandeja + pasta de gengibre) a cada 10 minutos, na primeira hora; a cada 20 minutos, na segunda e a cada 30 minutos, a partir da terceira hora até atingir peso constante, que resulta no teor de umidade de equilíbrio. Em seguida, a umidade final do conjunto (bandeja + pasta de gengibre) foi determinada por secagem em estufa a $105^{\circ} \mathrm{C}$, durante 24 horas.

Os experimentos foram realizados com as amostras em quadruplicata, o que confere maior confiabilidade ao teste. Durante os ensaios foram monitoradas as temperaturas de bulbo úmido e de bulbo seco do ar ambiente (psicrômetro).

As curvas de secagem do gengibre foram construídas a partir dos dados experimentais da umidade em base seca ( $\mathrm{X}_{\mathrm{bs}}$, $\mathrm{g}$ de água $\mathrm{g}^{-1}$ sólido seco) em relação ao tempo de secagem obtidos para as diferentes temperaturas.

A umidade do gengibre $\left(\mathrm{X}_{\mathrm{bs}}\right)$ será obtido a cada instante em termos de base seca através da Equação 1 (GEANKOPLIS, 1993).

$$
\mathrm{X}_{\mathrm{bs}}=\frac{\mathrm{M}_{\mathrm{umida}}-\mathrm{M}_{\text {seca }}}{\mathrm{M}_{\text {seca }}}
$$

Em que, $X_{b s}$ é a razão entre a massa de umidade e a massa de sólido isenta desta umidade em um determinado tempo em base seca $\left(\mathrm{gH}_{2} \mathrm{O} / \mathrm{g}\right.$ sol. seco), $\mathrm{M}_{\text {úmida }}$ é a massa do sólido e água presente na amostra (g) e $\mathrm{M}_{\text {seca }}$ é a massa seca (g) obtida em estufa a $105{ }^{\circ} \mathrm{C}$ por 24 h.

A umidade adimensional do gengibre $(Y)$ foi obtido a cada instante através da Equação 2 (GEANKOPLIS, 1993).

$$
Y=\frac{X_{b s}-X_{e q}}{X_{0}-X_{e q}}
$$

Em que, $\mathrm{X}_{\mathrm{eq}}$ é a umidade de equilíbrio da amostra; $\mathrm{X}_{0}$ é a umidade inicial da amostra.

Para avaliar a cinética do processo de secagem do gengibre foram construídas curvas de taxa de secagem para as diferentes condições de temperatura avaliadas, representada pela Equação 3: 


$$
R=\frac{d X}{d t}=-\left(\frac{m_{s}}{A}\right)\left(\frac{a X_{b s}}{d t}\right)
$$

Em que, $\mathrm{R}$ ou dX/dt é a velocidade ou taxa de secagem (g de $\mathrm{H}_{2} \mathrm{O} \mathrm{m}^{-2} \mathrm{~s}^{-1}$ ), t é o tempo (min), $\mathrm{m}_{\mathrm{s}}$ é a massa do material isento de umidade ( $\mathrm{g}$ ), $\mathrm{X}_{\mathrm{bs}}$ é a umidade do material ( $\mathrm{g}$ de $\mathrm{H}_{2} \mathrm{O}$ ( $\mathrm{g}$ de sólido seco $\left.)^{-1}\right)$ e A é a área da superfície exposta a secagem $\left(\mathrm{m}^{2}\right)$.

Os valores de $\left(\mathrm{dX}_{\mathrm{bs}} / \mathrm{dt}\right)$ foram calculados pela diferenciação numérica dos dados experimentais obtidos da umidade $\left(X_{b s}\right)$ em função do tempo (Equação 4).

$$
\frac{d X_{b s}}{d t}=\frac{X_{n-1}-X_{n}}{t_{n-1}-t_{n}}
$$

Em que, t é o tempo (min), $n$ é o número de leituras, $X_{n}$ e $X_{n-1}$ é a umidade $\left(\mathrm{g}_{\mathrm{H} 2 \mathrm{O}}\left(\mathrm{g}_{\text {massaseca }}\right)^{-1}\right)$ no tempo $n$ e no tempo $n-1$, respectivamente.

Os dados experimentais da umidade adimensional em função do tempo de secagem do gengibre foram ajustados utilizando os modelos matemáticos de Page, Newton e de Placa Plana de 5 termos disponíveis na literatura (PAGE, 1949; O'CALLAGHAN, 1971; CRANK, 1975). Para análise estatística utilizou-se o programa computacional Origin Pro, versão 8.0, e aplicação do teste Qui-Quadrado $\left(\chi^{2}\right)$ com significância de $5 \%(\alpha=0,05)$.

\section{RESULTADOS E DISCUSSÃO}

O processo de secagem da pasta de gengibre realizado nas temperaturas de 45,55 e $65{ }^{\circ} \mathrm{C}$ foi descrito empregando as curvas de secagem em termos da umidade adimensional (Y) em função do tempo (Figura 1).

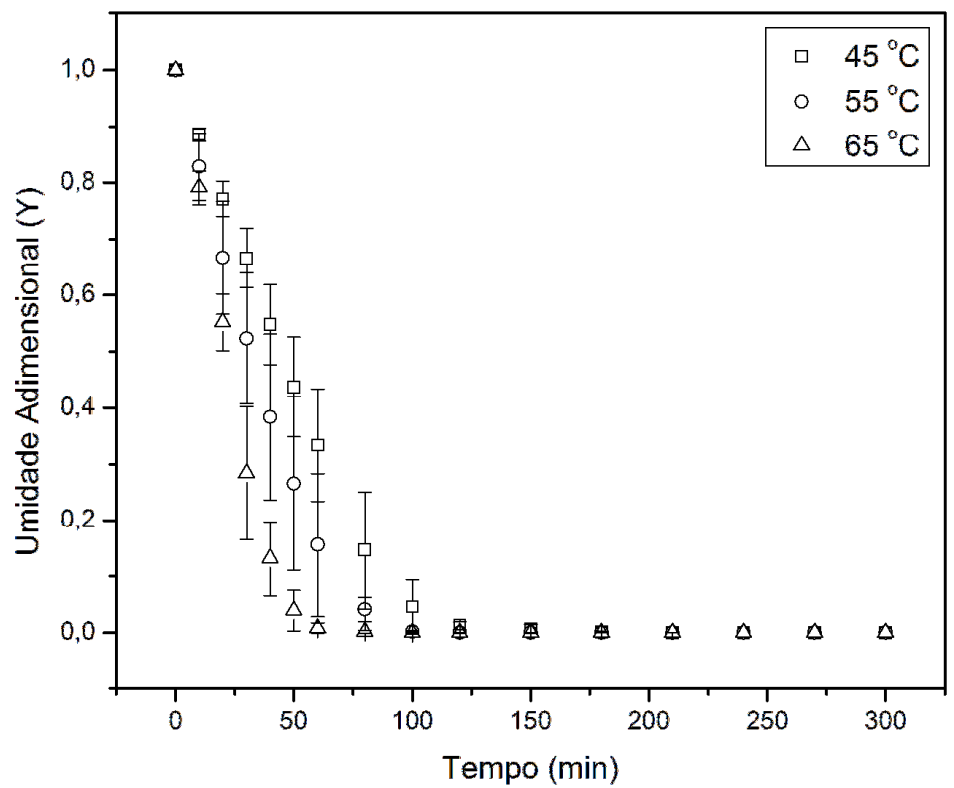

Figura 1 - Curva de umidade adimensional (Y) para a pasta de gengibre nas diferentes temperaturas. 
As curvas representam a diminuição do conteúdo de umidade da pasta de gengibre durante a secagem, em relação ao tempo de secagem (t). É possível perceber que a umidade do gengibre decai mais rapidamente no início do processo de secagem em todas as temperaturas avaliadas. Essa velocidade diminui com o passar do tempo em virtude da quantidade de umidade do produto ir reduzindo gradativamente até a umidade entrar em equilíbrio, tornando-se constante. A umidade relativa monitorada durante os experimentos de secagem foi em média $85 \%$.

Observa-se na Figura 1 que a temperatura possui grande influência na secagem da pasta de gengibre. Quanto maior a temperatura utilizada no processo, mais rápida a secagem e menor o tempo para atingir-se o equilíbrio. Há um aumento do potencial de secagem em decorrência do aumento da temperatura do ar pela ocasional diminuição da umidade relativa do ar de secagem.

Para a umidade adimensional em relação às temperaturas investigadas de 45,55 e 65 ${ }^{\circ} \mathrm{C}$ foram obtidos os tempos finais de secagem de 240, 210 e 120 minutos, respectivamente. Observa-se que o tempo para a secagem da pasta de gengibre a $65{ }^{\circ} \mathrm{C}$ corresponde a metade daquele necessário para realizar a secagem na temperatura de $45^{\circ} \mathrm{C}$.

A pasta de gengibre apresentou, após a secagem nas temperaturas de 45 e $55^{\circ} \mathrm{C}$,uma coloração amarela clara, sendo que na temperatura de $65{ }^{\circ} \mathrm{C}$ observou-se o escurecimento da camada superior da pasta, que entrava em contato com o ar de secagem. Assim, observandose a qualidade da pasta de gengibre seca obtida e o tempo de secagem, conclui-se que a temperatura de $55{ }^{\circ} \mathrm{C}$ se apresenta como a condição de operação mais apropriada para o processo investigado.

Segundo Prato (2010), o processo de secagem com o uso de ar em temperaturas relativamente elevadas pode introduzir mudanças nas propriedades do produto desidratado, tais como perda de compostos voláteis, degradação de compostos responsáveis pela pungência e formação de novos compostos.

O estudo da cinética de secagem do gengibre triturado não é muito comum e não se encontrou dados referentes à secagem da pasta de gengibre. Porém, ao compararem-se os resultados obtidos neste estudo com os obtidos por Prato (2010), verificou-se que os tempos para que o gengibre triturado atingisse a umidade de equilíbrio nas temperaturas de 45, 55 e $65{ }^{\circ} \mathrm{C}$ foram muito inferiores aos tempos obtidos pelo autor para o gengibre fatiado. Este gengibre foi submetido pelos pesquisadores ao processo de secagem convectiva com ar aquecido em bandejas à pressão atmosférica e atingiu a umidade de equilíbrio após 360, 340 e 300 minutos, respectivamente, para as temperaturas de 50,60 e $70{ }^{\circ} \mathrm{C}$.

Apesar das temperaturas de secagem quando comparadas não serem as mesmas, podese verificar que o tamanho das peças de gengibre influência diretamente no seu tempo de secagem, sendo que quanto maior a peça, mais tempo necessário para sua secagem.

Na Tabela 1 são apresentados os parâmetros cinéticos obtidos a partir do ajuste dos dados experimentais de secagem da pasta de gengibre para as três temperaturas avaliadas neste trabalho. 
Tabela 1 - Parâmetros obtidos dos modelos de secagem da pasta de gengibre em diferentes temperaturas

\begin{tabular}{ccccccc}
\hline Modelo & $\mathbf{T}\left({ }^{\mathbf{0}} \mathbf{C}\right)$ & $\mathbf{k}$ & $\mathbf{n}$ & $\mathbf{R}^{\mathbf{2}}$ & $\mathbf{S Q R}$ & $\boldsymbol{\chi} \mathbf{2}$ \\
\hline \multirow{3}{*}{ Page } & 45 & $2,48 \mathrm{E}-3$ & 1,503 & 0,997 & $5,92 \mathrm{E}-3$ & $4,23 \mathrm{E}-4$ \\
& 55 & $6,03 \mathrm{E}-3$ & 1,390 & 0,998 & $3,92 \mathrm{E}-3$ & $2,80 \mathrm{E}-4$ \\
& 65 & $4,38 \mathrm{E}-3$ & 1,663 & 0,999 & $1,57 \mathrm{E}-3$ & $1,12 \mathrm{E}-4$ \\
\hline \multirow{3}{*}{ Newton } & 45 & $1,85 \mathrm{E}-2$ & - & 0,971 & $5,76 \mathrm{E}-2$ & $3,84 \mathrm{E}-3$ \\
& 55 & $2,59 \mathrm{E}-2$ & - & 0,982 & $3,12 \mathrm{E}-2$ & $2,08 \mathrm{E}-3$ \\
& 65 & $4,06 \mathrm{E}-2$ & - & 0,969 & $4,80 \mathrm{E}-2$ & $3,20 \mathrm{E}-3$ \\
\hline \multirow{3}{*}{ Placa Plana } & 45 & $1,50 \mathrm{E}-3$ & - & 0,927 & $1,44 \mathrm{E}-1$ & $9,60 \mathrm{E}-3$ \\
& 55 & $2,13 \mathrm{E}-3$ & - & 0,950 & $8,66 \mathrm{E}-2$ & $5,77 \mathrm{E}-3$ \\
& 65 & $3,44 \mathrm{E}-3$ & - & 0,937 & $9,62 \mathrm{E}-2$ & $6,41 \mathrm{E}-3$ \\
\hline
\end{tabular}

Na Tabela 1 verifica-se que os modelos utilizados para ajustar os dados experimentais apresentaram valores de coeficientes de determinação $\left(\mathrm{R}^{2}\right)$ superiores a 0,92 , destacando-se entre eles como o melhor modelo o de Page, para o nível de significância adotado de $5 \%$.

Segundo Madamba et al. (1996), a constante de secagem (k) pode ser utilizada como um parâmetro de aproximação de forma a caracterizar o efeito da temperatura e está relacionada à difusividade efetiva no processo de secagem no período decrescente e à difusão líquida que controla o processo, enquanto n é a constante adimensional que permite obter uma equação mais precisa. Ainda de acordo com o autor, apenas o coeficiente de determinação não constitui bom critério para a análise de modelos não lineares, sendo considerados também os valores de qui quadrado $\left(\chi^{2}\right)$ e a soma residual dos quadrados (SQR).

O Qui Quadrado $\left(\chi^{2}\right)$ é um teste de hipóteses que se destina a encontrar um valor da dispersão para duas variáveis nominais, avaliando a associação existente entre variáveis qualitativas (CONTI, 2009). A partir dos valores de $\chi^{2}$ obtidos, percebe-se que para as temperaturas em estudo, todos os modelos obtiveram valores inferiores a 0,0096, significando que os dados experimentais e os obtidos pelos modelos não possuem muita dispersão, assim os dados experimentais podem ser aceitos como regidos pela teoria em questão. Dentre os modelos avaliados, o modelo de Page foi aquele que obteve os menores valores de $\chi^{2}$, bem como os menores valores dos desvios quadrados (SQR), significando uma menor dispersão entre os dados experimentais e teóricos.

Desta forma, para as condições experimentais em que o estudo foi realizado, o modelo de Page foi aquele que melhor ajustou os dados da cinética de secagem da pasta de gengibre em um intervalo de confiança de $95 \%$.

Outra importante análise é obtida a partir da curva da taxa de secagem em função do teor de umidade. As curvas das taxas de secagem para as temperaturas de 45,55 e $65{ }^{\circ} \mathrm{C}$ são apresentadas na Figura 2. 


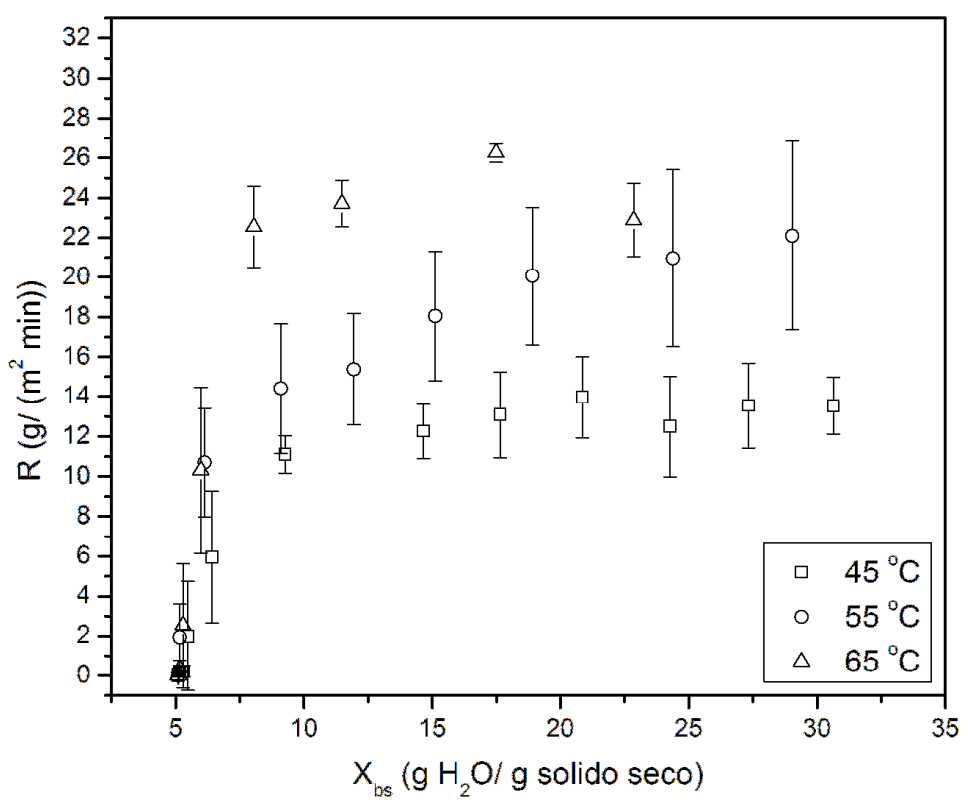

Figura 2 - Curvas de taxa de secagem para a pasta de gengibre nas temperaturas de 45, 55 e $65^{\circ} \mathrm{C}$.

Na Figura 3 percebe-se a influência da temperatura no processo de secagem da pasta de gengibre, onde para a temperatura de $65{ }^{\circ} \mathrm{C}$ se obteve a maior taxa de secagem. As curvas da taxa de secagem da pasta de gengibre apresentaram o período de taxa constante e o período de taxa decrescente que se estendeu até a umidade de equilíbrio $\left(\mathrm{X}_{\mathrm{e}}\right)$ do processo. Os resultados obtidos são característicos de um material que contém muita umidade, como o gengibre. No período de taxa constante, a água livre abundante presente no gengibre é evaporada em uma velocidade constante, atingindo o período de taxa decrescente se tem a água ligada migrando do interior da pasta de gengibre a sua superfície para ser evaporada. Esse período indica que a taxa de evaporação (movimento do líquido) é controlada pela difusão interna de umidade.

\section{CONCLUSÃO}

Os tempos de secagem da pasta de gengibre obtidos foram de 240, 210 e 120 minutos para as temperaturas de 45,55 e $65{ }^{\circ} \mathrm{C}$, respectivamente. A temperatura de $55{ }^{\circ} \mathrm{C}$ foi estabelecida como a melhor dentre as avaliadas em termos de qualidade visual do gengibre seco. O modelo de Page foi o mais satisfatório no ajuste dos dados experimentais da cinética de secagem da pasta de gengibre em todas as temperaturas avaliadas. A taxa de secagem do gengibre apresentou um período de taxa constante e um período de taxa decrescente, sendo a taxa de secagem influenciada pela temperatura.

\section{REFERÊNCIAS}

CONTI, F. Qui Quadrado. Laboratório de Informática - ICB - UFPA, 2009. Notas de Aula.

CRANK, J.The mathematics of diffusion. 2. ed. Oxford: Claredon Press, 1975. 
ELPO, E. R. S.; NEGRELLE, R. R. B. Zingiber officinale Roscoe: Aspectos botânicos e ecológicos. Visão Acadêmica, Curitiba, v. 5, n. 1, p. 27-32, Jan.- Ju, 2004.

GEANKOPLIS, C. J. Transport Processes and Unit Operations. 3. ed. Boston: Prentice Hall, p. 754-794, 1993.

GOUVEIA, J. P; ALMEIDA, F. A. C; MURR, F. E. X. Estudo da difusividade e do encolhimento do gengibre (Zingiber officinalle, Roscoe) durante a secagem. Revista Brasileira de Produtos Agroindustriais, v. 1, n. 1, p. 51-58, 1999.

JÚNIOR, P. C. A; CORRÊA, P. A. Comparação de modelos matemáticos para descrição da cinética de secagem em camada fina de sementes de feijão. Revista Brasileira de Engenharia Agrícola e Ambiental, v. 3, n. 3, p. 349-353, 1999.

MADAMBA,P. S.; DRISCOLL, R. H.; BUCKLE, K. A. Thin layer drying characteristics of garlic slices. Journal of Food Engineering, v. 29, n. 1, p. 75-97, 1996.

MENDES, M. O. Serviço Brasileiro de Respostas Técnicas - Resposta Técnica: O cultivo de gengibre - 2005. Site visitado em 03/09/2013. Disponível em: http://www.sbrt.ibict.br.

NEGRELlE, R. R.B.; ELPO, E. R.S.; RUCKER, N. G.A. Análise prospectiva do agronegócio gengibre no estado do Paraná. Horticultura Brasileira, Brasília, v. 23, n. 4, Dezembro, 2005.

O'CALLAGHAN, J. R.; MENZIES, D. J.; BAILEY, P. H. Digital simulation of agricultural drier performance. Journal of Agricultural Engineering Research, v. 16, n 3, p. 223-244. 1971.

PAGE, G. E. Factors influencing the maximum of air drying shelled corn in thin layer. Dissertação (Mestrado), Purdue University, Indiana. 1949.

PARK, K. J. B.; ANTONIO, G. C.; OLIVEIRA, R. A. Conceitos de processo e equipamentos de secagem. Apostila. Campinas-SP, Março de 2007.

PRATO, T. S. Influência da secagem sobre compostos medicinais e de pungência do gengibre. Universidade Estadual Paulista, Instituto de Biociências, Letras e Ciências Exatas. Dissertação de Mestrado. São José do Rio Preto, 2010.

RESENDE, O.; ARCANJO, R. V.; SIQUEIRA, V. C.; RODRIGUES, S. Modelagem matemática para a secagem de clones de café (Coffea canephora Pierre) em terreiro de concreto Pierre em terreiro de concreto. Acta Scientiarum. Agronomy, Maringá, v. 31, n. 2, p. 189-196, 2009. 